\title{
ESTÁGIO CURRICULAR OBRIGATÓRIO NA FARMÁCIA ESCOLA DA FACULDADE DE FARMÁCIA DA UNIVERSIDADE FEDERAL DE GOIÁS
}

Luciana Resende Prudente, farmacêutica esp., Farmácia Escola-Universidade Federal de Goiás, lu.rp@bol.com.br

Suzana de Sousa Stival, farmacêutica, Farmácia Escola-Universidade Federal de Goiás

Núsia Luísa Barbosa farmacêutica Ms., Coordenadora da Farmácia Escola-Universidade Federal de Goiás

Eliane de Vasconcelos Caixeta, farmacêutica esp., Farmácia Escola-Universidade Federal de Goiás

Nathalie de Lourdes Souza Dewulf, professora da Faculdade de Farmácia da Universidade Federal de Goiás

Tatyana Xavier Almeida Matteucci Ferreira, farmacêutica Ms., Farmácia Escola-Universidade Federal de Goiás

RESUMO: A Farmácia Escola da Universidade Federal de Goiás (FE-UFG) é uma instituição pública, fundada em 1996 e tem como objetivos principais desenvolver atividades de ensino, pesquisa e extensão nas áreas magistral e de dispensação de especialidades farmacêuticas, cosméticos e correlatos; proporcionado assim ao aluno condições adequadas para o desenvolvimento do seu perfil profissional e consolidando o papel da Farmácia como estabelecimento de saúde frente a comunidade. O estágio curricular obrigatório tem carga horária de 128h, mas a percepção tanto da equipe da FE, quanto dos alunos, é de que o período de estágio é curto, o que limita, em certa proporção, a aquisição de experiência e obtenção de maior segurança na realização das atividades desenvolvidas. Outro fator limitante do estágio, é o pequeno número de pacientes que freqüentam o estabelecimento, o que se deve à pouca visibilidade que a Farmácia tem frente ao público em geral. A fim de tornar a FE conhecida, passamos a contar com o auxilio da Assessoria de Comunicação Social da UFG (ASCOM) que tem como principal atribuição a divulgação institucional. Através dessa parceria estão programadas atividades de divulgação a serem realizadas durante todo o ano de 2012. Acredita-se que através da implantação das ações até aqui descritas, além de vários projetos de extensão que terão início nesse ano, será possível alcançar o objetivo de dar mais visibilidade à Farmácia Escola; consequentemente, espera-se uma maior demanda dos serviços oferecidos e, portanto, mais produtividade em todos os setores e mais oportunidades de aprendizagem aos estagiários.

Palavras-chave: educação em farmácia. farmácia comunitária. ensino superior.

ABSTRACT: The Farmacia Escola of Goiás Federal University (FE - UFG) is a public institution, founded in 1996, and has a main objective to develop teaching research and outreach projects, in the areas 
of magistral manipulation, dispenseing of medicinal products, cosmetics and related items. This offers students the adequate conditions for development of their professional profile and consolidating a role of pharmacy and healthcare facilities in the community. The training curriculum requires 128 hours, but both, the FE team and the students, perceive that probationary period is short. To some extent, this limits the acquisition of experience and obtaining greater security in carrying out activities. Another limiting factor of the training is the small number of patients who frequent the establishment. This is due to poor visibility that the pharmacy front has to the general public. In order to make known the FE, we count on the help of Social Communication Agency of the UFG, whose main task is the institutional promotion. Through this partnership outreach, activities are scheduled to be held throughout the year 2012. It is believed that through the implementation of the actions described here, along with the several outreach projects that will begin this year, we'll be able to achieve the goal of the giving more visibility to Farmácia Escola and, accordingly, we expect a greater demand for services offered and therefore more productivity in all sectors and more learning opportunities for trainees.

Keywords: Pharmacy education, community pharmacy, higher education.

\section{INTRODUÇÃO}

A Farmácia Escola da Universidade Federal de Goiás (UFG) é uma instituição pública, fundada em 1996 e tem como objetivos principais desenvolver atividades de ensino, pesquisa e extensão nas áreas magistral e de dispensação de especialidades farmacêuticas, cosméticos e correlatos. De acordo com seu regimento interno a Farmácia Escola (FE) tem como principais objetivos: Servir como campo de estágio na formação do farmacêutico; Prestar atendimento farmacêutico à comunidade em geral com orientação sobre o uso racional dos medicamentos.

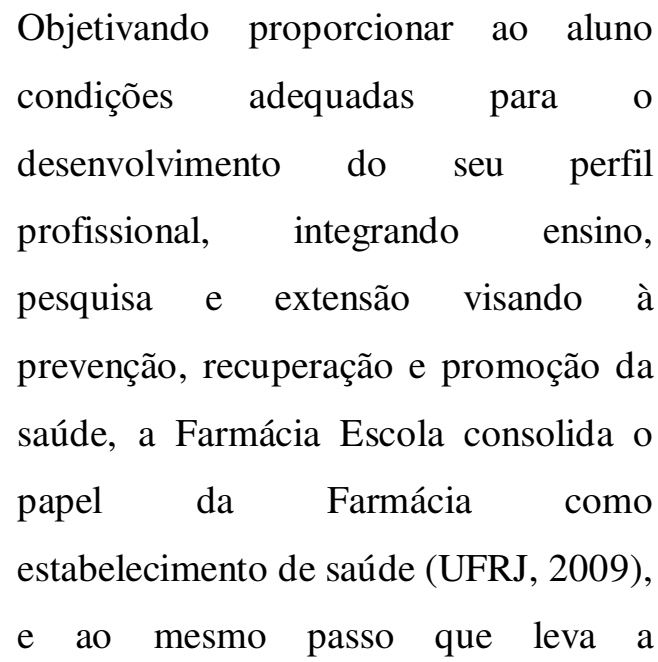
Universidade a atuar e interatuar com a comunidade (ROSSIGNOLI et. AL., 2003). Além disso, a Farmácia Escola é também palco para pesquisa em várias áreas de atuação do farmacêutico, como a Atenção Farmacêutica, farmacovigilância, farmacotécnica, entre outras. 
A farmácia magistral é o estabelecimento onde, sob encomenda, manipulam-se formulas magistrais $\mathrm{e}$ oficinais, de maneira artesanal e não seriada (FERREIRA, 2002;BRASIL RDC $n^{\circ}$ 67,2007). Destaca-se pela produção de formas farmacêutica e dosagens diferentes das padronizadas pela indústria farmacêutica, além disso, possibilita a associação de princípios ativos na mesma formulação e o ajuste de doses conforme a necessidade de cada paciente, o que irá proporcionar uma terapêutica personalizada e segura (BATISTUZZO et al., 2002).

As instalações da FE estão de acordo com a legislação vigente, incluindo a RDC n067/2007 e conta com laboratórios para produção de medicamentos sólidos, semi-sólidos e líquidos e homeopáticos. O quadro de funcionários é composto por 6 farmacêuticas, 2 bolsistas do curso de farmácia da UFG, 2 funcionários administrativos e em média 16 estagiários envolvidos nos setores de atendimento e manipulação. E ainda, a FE conta com a participação efetiva de professores referentes à cada área de atuação.

A FE atende por dia uma média de 30 prescrições para manipulação de clientes oriundos do Hospital das Clinicas da UFG, do Sistema Único de Saúde (SUS), Associação de Combate ao Câncer em Goiás (ACCG) e rede privada.

\section{METODOLOGIA}

O estágio curricular obrigatório, com carga horária de $128 \mathrm{~h}$, dos alunos do curso de Farmácia tem início com um treinamento geral, o qual é ministrado por uma das farmacêuticas. Nesse primeiro treinamento o estagiário toma conhecimento dos vários documentos que normatizam o estágio, esclarecendo quais os direitos e deveres da instituição e também do estagiário.

Os documentos que normatizam o estágio são: Regulamento do Estágio Supervisionado na Farmácia Escola da Faculdade de Farmácia da UFG, elaborado pela Farmácia Escola de acordo com as normas estabelecidas pela Pró-Reitoria de Graduação da UFG; Termo de Compromisso de Estágio, Plano de Atividades de Estágio, Relatório de Atividade de Estágio, Ficha de Frequência de Estágio Curricular e Ficha de Avaliação do Estagiário, elaborados pela Pró-Reitoria de Graduação da UFG. 
$\mathrm{Na}$ sequência, treinamentos específicos sobre cada setor e as respectivas atividades a serem realizadas são ministrados pela farmacêutica supervisora, a qual também é responsável pela elaboração de duas atividades teóricas e ainda pela avaliação do desempenho de cada indivíduo no término do período de estágio.

Durante o estágio o aluno receberá atividades teóricas específicas de cada setor em que se encontra, através das quais poderá aplicar os conhecimentos adquiridos durante o estágio e terá também a oportunidade de realizar buscas no acervo da FE. Essas atividades são corrigidas, devolvidas para cada aluno e então tem-se um momento de discussão para esclarecimentos de duvidas e checagem da aprendizagem. Além das discussões sobre cada exercício, também ocorre discussões conceituais sob a supervisão dos docentes.

A avaliação do desempenho compreende aspectos profissionais (conhecimento, execução das atividades, interesse e iniciativa) e aspectos comportamentais (assiduidade, disciplina, cooperação, responsabilidade e ética profissional).
A nota geral do aluno em cada setor corresponde à média da média das notas das atividades teóricas com a média das notas da avaliação do desempenho.

\section{RESULTADOS}

Durante os quinze anos de funcionamento da Farmácia Escola passaram por esta instituição cerca de 1200 estagiários.

Pode-se perceber que os profissionais que por aqui passaram tem a Farmácia Escola como referência tanto no que diz respeito à excelência na manipulação de medicamentos e produtos quanto sobre assuntos regulatórios, pois com certa freqüência entram em contato com a equipe para sanar dúvidas sobre o setor.

A percepção atual, tanto da equipe quanto dos alunos, é de que o período de estágio é curto, o que limita, em certa proporção, a aquisição de experiência e obtenção de maior segurança na realização das atividades aqui desenvolvidas. A carga horária de $128 \mathrm{~h}$ é dividida nos setores de manipulação (laboratório de semi-sólidos e liquídos e laboratório de sólidos) e setor de atendimento. Sendo assim, o estagiário passa uma média de dez dias em cada setor. Além disso, devido também à 
carga horária limitada, não é possível que os alunos acompanhem as atividades dos setores de controle de qualidade e administração.

A equipe da FE tem consciência de que o pequeno número de pacientes que freqüentam o estabelecimento também é um fator limitante ao desenvolvimento das atividades do estágio. Em parte, isso se deve a pouca visibilidade que a Farmácia tem até mesmo dentro da própria Universidade e também com relação ao público em geral.

\section{DISCUSSÃO}

Os fatores que limitam o bom desenvolvimento do estágio na FE são a carga horária de estágio reduzida e o número pequeno de clientes.

Em relação à carga horária, a nova grade do curso, a ser implantada em breve, contempla $160 \mathrm{~h}$ de estágio curricular obrigatório em Farmácia Comunitária. Uma carga horária maior permitirá ao estagiário oportunidade de se desenvolver e adquirir mais segurança nas atividades realizadas.

Em relação ao número de pacientes, a principal causa detectada pela equipe da FE é a pouca visibilidade da mesma, verificou-se a necessidade emergencial de se criar estratégias e elaborar planos de ação corretivos e preventivos, para sanar esse problema.

A fim de tornar a FE conhecida pela comunidade universitária e publico em geral, passamos a contar com o auxilio da Assessoria de Comunicação Social da UFG (ASCOM) que tem como principal atribuição a divulgação institucional. Através dessa parceria estão programadas atividades de divulgação a serem realizadas durante todo o ano de 2012 e compreendem a elaboração de uma nova logomarca, cartazes, folders, cartões de visita, outdoors, visando dar a conhecer pela comunidade a farmácia e os serviços prestados.

A confecção do material de divulgação se dará através da Gráfica da UFG (CEGRAF), uma vez que a Farmácia Escola é cadastrada como projeto de extensão.

O projeto de extensão "Orientação Farmacêutica aos Prescritores de Medicamentos Manipulados" tem, além do caráter educativo, uma possibilidade de divulgação dos serviços prestados pela Farmácia aos prescritores. $\mathrm{O}$ projeto consiste na elaboração de um material com orientações aos 
prescritores constituindo uma tentativa de estabelecer um vínculo multiprofissional entre os farmacêuticos da Farmácia Escola da UFG e os profissionais prescritores: médicos, odontólogos e nutricionistas.

Outra ação a ser executada em 2012, é a implantação do serviço de Atenção Farmacêutica para usuários de Medicamentos, através do qual prestaremos serviços farmacêuticos que constam da RDC n044/2009. Esta ação encontra-se em fase de elaboração e análise da viabilidade.

Ainda outra possibilidade para aumentar a produtividade na FE é oportunidade

\section{REFERÊNCIAS BIBLIOGRÁFICAS}

BATISTUZZO, José Antônio de Oliveira.; ITAYA, Masayuki; ETO, Yukiko; Formulário Médico Farmacêutico. 2. Ed. São Paulo: Tecnopress, 2000. P. 23

BRASIL. Resolução da Diretoria Colegiada, no 67, de 8 de outubro de 2007. Dispõe sobre Boas Práticas de Manipulação de Preparações Magistrais e Oficinais para uso humano em farmácias.

BRASIL. Resolução da Diretoria Colegiada, no 44, de 17 de agosto de 2009. Dispõe sobre Boas Práticas Farmacêuticas para o controle sanitário do funcionamento, da dispensação e da comercialização de produtos e da prestação de serviços farmacêuticos em de se firmar um convênio com a da Secretaria Municipal de Saúde para manipulação de fórmulas prescritas na rede pública e que não constam na Relação Municipal de Medicamentos Essenciais (REMUME).

Acredita-se que através da implantação das ações até aqui descritas, será possível alcançar o objetivo de dar mais visibilidade à Farmácia Escola, consequentemente, espera-se uma maior demanda dos serviços oferecidos e, portanto, mais produtividade em todos os setores e mais oportunidades de aprendizagem aos estagiários.

farmácias e drogarias e dá outras providências.

FERREIRA, Anderson de Oliveira; BRANDÃO, Marcos Fernandes; SILVA, Maria Arabela Dias de Castro Calil. Guia Prático da Farmácia Magistral. 2 ed.Juiz de Fora, Brasil: Pg $17,2002$.

ROSSIGNOLI, P.; CORRER, C. J.; FERNANDÉZ-LLIMÓS F. Interesse dos acadêmicos nas atividades de estágios em farmácia escola em Curitiba - Brasil. Seguim. Farmacoter. 1(2): 62 $-68,2003$.

UFRJ. II Encontro Nacional de Farmácias Universitárias. Universidade Federal do Rio de Janeiro, 2009 Disponível em: $<$ http://www.farmaciauniversitaria.ufrj. br/encontro.html>. Acesso em $22 / 07 / 201$ 